of Tristan da Cunha. ${ }^{1}$ Our findings were based on general clinical examinations of the islanders carried out during the first three months of their period of involuntary exile in England.

Some of the findings of a specialized psychiatric and sociological inquiry have now been published by Rawnsley and Loudon." We should like to draw attention to certain important discrepancies between these findings and our own impressions of the mental state of the Tristan people. We reported that they were "... noticeably free, with very few exceptions, of anxieties and worries. . . ." Rawnsley and Loudon had the opportunity to make an intensive study over the subsequent months. It was found that there were four current cases $(2.1 \%)$ of psychotic disorder, and that $24 \%$ of the adults suffered from headache precipitated by anxiety and worry. This symptom was endemic both on Tristan and in England. There was also shown to be a most interesting association between the occurrence of headache at the present day and the occurrence of an epidemic of hysteria which affected over $10 \%$ of the population in 1937

When they arrived here their polite friendliness in a new and strange environment, together with mounting nostalgia, led them to present an idealized picture of themselves and their life on Tristan which more detailed study has corrected.-I am, etc.,

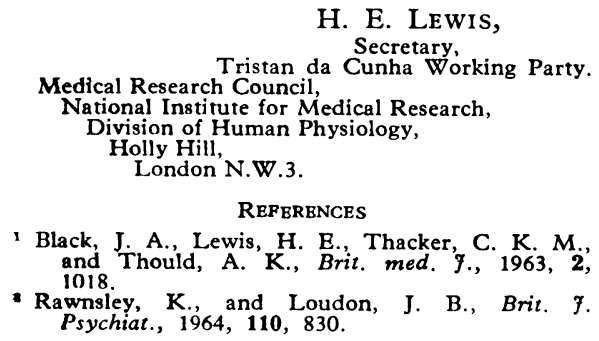

\section{Cystic Disease and Carcinoma of the Breast}

SIR,-There is one important piece of evidence, which you do not mention, which would strengthen the conclusion of your leading article (20 February, p. 469) that " these patients wish for reassurance, and in our present state of knowledge they should receive it." I refer to the experience, for the most part unrecorded, of large numbers of surgeons all over the world who for several decades now have been treating cysts of the breast by aspiration, and who have not seen any particular tendency to carcinoma in these patients. Nurick and I some years ago ${ }^{1}$ pointed out a fallacy which is present in most series purporting to show that cysts of the breast predispose to carcinoma-namely, that the authors do not exclude from their figures the small group of cysts of the breast in which intraductal papillary carcinomas by a combination of some irritant action and the effusion of varying amounts of blood actually cause a cyst. The much more common simple cysts of the breast have quite different clinical features, and, if one may extrapolate from the work of Hayward and Parks which you mention, ${ }^{2}$ are best regarded as chance temporary upsets of normal secretoryabsorptive processes during the phase of breast involution. Finally, may I make a plea that, since the condition is paraphysio- logical rather than pathological, the reassurance which you rightly say these patients should receive would be strengthened if, instead of using the term "cystic disease," we referred to the condition as either " simple cysts" or "involution cysts" ?-I am, etc.,

$$
\text { London W.1. }
$$$$
\text { David H. Patey. }
$$
REPERENCES ${ }^{1}$ Patey, $\mathrm{D}_{\text {. H., }}$ and Nurick, A. W., Brit. med. 7.,
1953, is.
${ }^{2}$ Hayward, J. L., and Parks, A. G., Endocrine
Aspects of Breast Cancer, 1958, p. 133, ed. by
A. R. Luwrie. Livingstone, Edinburgh.

\section{Pleural Effusion and Breast Cancer}

SIR,-The observation by Dr. E. H. Porter (23 January, p. 251) that pleural effusions secondary to cancer of the breast are more commonly ipsilateral than contralateral is, of course, not new. This point was mentioned in the columns of your journal in 1953 in a paper written by me in collaboration with Dr. Frank Ellis, ${ }^{1}$ and I have little doubt that it was made by others before us.

Out of 159 cases of breast cancer with pleural effusion who died between 1954 and 1960 at the Peter MacCallum Clinic, Melbourne, 95 effusions were ipsilateral, $41 \mathrm{con}$ tralateral, and 23 bilateral in their onset. Like the Christie Hospital, Manchester, figures, our larger series showed that the excess of ipsilateral over contralateral effusions is seen in all years of follow-up after the first treatment, even after five years (see Table I). It is seen in the primarily operated cases (Stages 1 and 2), and in the primarily irradiated cases (Stages 3 and 4 ). It is seen in operated cases, both when the scar was irradiated post-operatively and when it was not (see Table II). This latter observation does not exclude the likelihood that the incidence of pleural effusion may be decreased by

\begin{tabular}{c|rrrrrr} 
TABLE I \\
\hline Years & 1 & 2 & 3 & 4 & 5 & $5+$ \\
\hline Stages 1 and $2\left\{\begin{array}{l}\text { Ipsilat... } \\
\text { Contralat. }\end{array}\right.$ & 22 & 12 & 13 & 5 & 5 & 13 \\
Stages 3 and $4\left\{\begin{array}{l}\text { Ipsilat... } \\
\text { Contralat. }\end{array}\right.$ & 13 & 7 & 3 & 1 & 0 & 1 \\
& 1 & 3 & - & - & - & 1 \\
\hline
\end{tabular}

\begin{tabular}{|c|c|c|c|c|c|c|c|}
\hline \multicolumn{2}{|c|}{ Years } & 1 & 2 & 3 & 4 & 5 & $5+$ \\
\hline Surgery alone & $\left\{\begin{array}{l}\text { Ipsilat... } \\
\text { Contralat. }\end{array}\right.$ & $\begin{array}{r}14 \\
5\end{array}$ & $\begin{array}{l}6 \\
8\end{array}$ & $\begin{array}{l}9 \\
3\end{array}$ & $\begin{array}{l}3 \\
3\end{array}$ & $\begin{array}{l}4 \\
2\end{array}$ & $\begin{array}{l}8 \\
6\end{array}$ \\
\hline $\begin{array}{l}\text { Surgery and } \\
\mathrm{R} / \mathrm{T} \text { scar }\end{array}$ & $\left\{\begin{array}{l}\text { Ipsilat.... } \\
\text { Contralat. }\end{array}\right.$ & $\begin{array}{l}8 \\
2\end{array}$ & $\begin{array}{l}6 \\
1\end{array}$ & $\begin{array}{l}4 \\
3\end{array}$ & $\begin{array}{l}2 \\
1\end{array}$ & $\frac{1}{2}$ & 5 \\
\hline
\end{tabular}

irradiation of the scar post-operatively, but it would require a randomly selected series to establish this point, and ours is not.

I agree with Dr. Porter that clinical evidence suggests that the development of a malignant pleural effusion in breast cancer is more likely to be due to lymphatic permeation than to haematogenous spread. This is supported by my observation that in the 106 cases developing an effusion postoperatively there was associated evidence of local recurrence in 74-a proportion of $69 \%$ (skin nodules in 53, ipsilateral supraclavicular nodes in 39, opposite breast invasion in 12 , opposite axillary-node involvement in 9 , and ipsilateral axillary-node recurrence in 2 cases). These local recurrences were usually closely associated in time with the pleural effusion and actually appeared simultaneously with the effusion in 22 of the 73 cases. The development of a pleural effusion following mastectomy may suggest, therefore, as does the development of local recurrence, injudicious selection for radical surgery.-I am, etc., Peter MacCallum Clinic, BAsIl A. STOLL.
Melbourne, Australia.

\section{REFERENCE}

Stoll, B. A., and Ellis, F., Brit. med. F., 1953, 2, 796 .

\section{Hepatic Coma Due to Liver Metastases}

SIR,-Dr. A. Paton (30 January, p. 316) and Dr. N. R. Pal and his colleagues (16 January, p. 168) discuss coma due to hepatocellular failure when liver tissue is extensively replaced by metastases. Another cause of coma in such patients may be hypoglycaemia resulting from severe depletion of glycogen stores in the liver. The rarity of this is pointed out by Professor Sheila Sherlock. ${ }^{1}$ Woodward and $\mathrm{Fry}^{2}$ found that patients with carcinoma had an average blood sugar of $20 \mathrm{mg} . / 100 \mathrm{ml}$. higher than that of normal controls, so it is reasonable to suppose when hypoglycaemia occurs in the presence of liver secondaries that it is due to disturbance of hepatic function.

The following brief case report will further emphasize this.

The patient, a widow aged 68 , whose husband died six years previously with carcinoma of the stomach, presented with a short history of anorexia, upper abdominal pain, and weight loss. She was found to have a hard, nodular, enlarged liver, and carcinoma of the stomach with hepatic metastases was suspected. Investigations showed serum bilirubin $0.3 \mathrm{mg} . / 100 \mathrm{ml}$. and alkaline phosphatase of $31.5 \mathrm{~K}-\mathrm{A}$ units. She was fasted prior to a barium-meal examination and collapsed in the radiology department, at the same time becoming pale, sweating, and aphasic. The right plantar response was equivocal, and it was thought possible that she had sustained a cerebrovascular accident. Lumbar puncture, however, revealed a cerebrospinal fluid sugar content of $17 \mathrm{mg} . / 100 \mathrm{ml}$, and shortly afterwards the blood sugar was $30 \mathrm{mg} . / 100 \mathrm{ml}$. She improved rapidly following intravenous infusion of $50 \%$ glucose, and one week later was fit for a laparotomy (Mr. L. Lancaster) which confirmed an inoperable carcinoma of the stomach with extensive hepatic infiltration. Two weeks later she again became comatose in the early hours of the morning, improving after glucose water was given into the stomach by Ryle's tube, but half an hour later she relapsed and died.

Post-mortem examination revealed a large fungating carcinoma of the fundus with extensive replacement of liver tissue by secondary deposits. -I am, etc.,

GARE
Caernarvon \& Anglesey Hospital,
Bangor, Caernarvonshire.

\section{REFBRENCES}

Sherlock, S. Diseases of the Liver and Biliary System, p. 424, 3rd ed. 1963. Blackwell, Woodward, G. E., and Fry, E. G. Biochem. 7., 1932, 26, 889.

\section{Inaccuracies of Statistics}

SIR,-It was encouraging to see from your leading article (13 February, p. 401) recognition of the inaccuracies of hospital statistics. Unfortunately, although technically more accurate, the same analysis could also be applied to the returns of the Registrar 